\title{
REFLEXÕES PRELIMINARES ALICERÇADAS NO PROGRAMA MAIS EDUCAÇÃO E NOVO MAIS EDUCAÇÃO
}

\author{
Paula Mieco Koizumi Masuyama, Marcela Côrrea Tinti \\ Universidade Estadual Paulista - UNESP.
}

\begin{abstract}
RESUMO
A temática Educação Integral tem conquistado espaço no âmbito das pesquisas educacionais e há alguns anos permanece ativa na agenda governamental. Nesse contexto, o presente trabalho tem como objetivo discutir as possibilidades de melhoria do aprendizado de acordo com os propósitos dos programas Mais Educação e Novo Mais Educação. Como resultado, constatamos a emergência de, primeiramente, compreender os princípios da educação integral para que a política de fato seja configurada para melhorar a aprendizagem e, assim, possibilitar a ressignificação do espaço escolar e da prática pedagógica.

Palavras-chave: Educação Integral. Aprendizado. Programa Mais Educação. Programa Novo Mais Educação.

\section{PRELIMINARY REFLECTIONS CHOSEN ON THE PROGRAM FOR MORE EDUCATION AND NEW MORE EDUCATION}

\begin{abstract}
The theme of Integral Education has gained space in the field of educational research and for some years remains active in the governmental agenda. In this context, the present work aims to discuss the possibilities of improving learning according to the purposes of the More Education and New More Education programs. As a result, we see the emergence of, firstly, understanding the principles of integral education so that policy is actually configured to improve learning and, thus, make it possible to redefine school space and pedagogical practice.
\end{abstract}

Keywords: Integral Education. Learning. More Education Program. New More Education Program. 


\section{INTRODUÇÃO}

Segundo Pacheco (2008), discutir a proposta de Educação Integral (EI) não é tão simples uma vez que além de um sistema legal, jurídico existe uma questão conceitual.

Na legislação brasileira, conforme descreve o documento norteador do MEC (2014, p. 4), já consta a El pois

[...] pode ser apreendida em nossa Constituição Federal, nos artigos 205, 206 e 227; no Estatuto da Criança e do Adolescente (Lei no 9089/1990); na Lei de Diretrizes e Bases (Lei no 9394/1996), nos artigos 34 e 87; no Plano Nacional de Educação (Lei no 10.179/01) e no Fundo Nacional de Manutenção e Desenvolvimento do Ensino Básico e de Valorização do Magistério (Lei no 11.494/2007).

Podemos verificar que, de forma gradual, o governo foi consolidando a El no Brasil, principalmente, com o Plano Nacional de Educação e a instituição do Programa Mais Educação pela Portaria Interministerial $n=17 / 2007$ e pelo Decreto $n^{\circ} 7.083 / 2010$ (MEC, 2014).

Neste último, o MEC (2014) tem como objetivo ampliar o tempo, espaço e oportunidades incentivando a participação de diferentes atores, ou seja, indo além dos muros da escola. Tal objetivo vai ao encontro do estabelecido no artigo 205 da Constituição Federal de 1988 que entende a educação como um direito de todos, sendo que o Estado, família e sociedade tem o dever de favorecer o pleno desenvolvimento da pessoa entendendo o ser humano em suas múltiplas dimensões cada um com as suas peculiaridades.

Diante desta contextualização, ao investigar a temática, nos deparamos com uma multiplicidade de concepções a respeito da El, pois segundo o documento norteador do Ministério da Educação e Cultura (MEC, 2009, p. 6):

[...] percebem-se diferentes concepções e práticas, alicerçadas em visões sociais de mundo por vezes complementares, por vezes contraditórias, que necessitam urgentemente de um mapeamento, no sentido de descrever essas múltiplas construções político-sociais, teórico-epistemológicas e pedagógicas.

A partir dessa premissa, complementamos com os estudos de Cavaliere (2010) que realiza uma trajetória histórica da El e refere que desde o início do século XX existiam diferentes expectativas em relação à educação escolar oriundas de diferentes ideologias, a saber: integralista, socialista e liberalista.

Os integralistas, segundo a autora, concebiam "a educação integral para o homem integral" (CAVALIERI, 2010, p. 249) apresentando um caráter autoritário e doutrinador por conceber a El uma ação doutrinária definindo a formação como "um processo de conversão a uma verdade já estabelecida" (CAVALIERI, 2010, p. 250).

A corrente socialista, contrária ao integralismo, traz ideais anarquistas acompanhando o movimento internacional concebendo que a formação do aluno deve ser completa, assumindo um caráter emancipador e questionador (RINALDI; SILVA, 2017; CAVALIERI, 2010).

Por sua vez, surgem o movimento denominado pela autora de liberalistas com um caráter emancipador e revolucionário e defendiam a renovação da escola por meio de práticas democráticas abrangendo o aluno em todas as suas dimensões.

De acordo com Cavalieri (2010, p. 252), os intelectuais reformistas defendiam a ampliação das funções da escola e elaboraram o documento Manifesto dos Pioneiros da Educação Nova de 1932 propondo uma renovação educacional do país. Neste documento a educação integral é vista como um "direito do indivíduo a uma educação pública que alcance diversas dimensões de sua formação". 
Face a este contexto, este trabalho tem como objetivo discutir as possibilidades de melhoria do ensino alicerçados de acordo com os propósitos dos programas Mais Educação e Novo Mais Educação, pois tratar a respeito da El requer entender a complexidade do tema, assim como as razões de voltar a fazer parte da agenda governamental e substituir a proposta anteriormente delimitada. Para tanto, é necessário saber, suscintamente, sobre o ciclo das políticas públicas.

\section{METODOLOGIA}

Por se tratar de um estudo comparativo entre os programas Mais Educação e Novo Mais Educação versando a Educação Integral, este caracteriza-se como uma pesquisa bibliográfica entendida como um conjunto de procedimentos ordenados em busca de soluções (MINAYO, 2002).

Este tipo de pesquisa possibilita chegar às respostas de uma problematização a partir referencial teórico pesquisado e investigado.

Para Gil (2012, p. 48) "a principal vantagem da pesquisa bibliográfica reside no fato de permitir ao investigador a cobertura de uma gama de fenômenos muito mais ampla do que aquela que poderia pesquisar diretamente", além de ser indispensável para conhecer fatos passados.

\section{RESULTADOS}

A temática El está presente na meta 6 do Plano Nacional de Educação. Parente (2017) considera uma "janela política" importante, pois visa "oferecer educação em tempo integral em, no mínimo, $50 \%$ (cinquenta por cento) das escolas públicas, de forma a atender, pelo menos $25 \%$ (vinte e cinco por cento) dos (as) alunos (as) da educação básica" (BRASIL, 2014d).

Segundo o MEC/Secad (2009, p. 11), a implementação de uma política de El no país está relacionada quando detecta-se que a

discrepância revela profundas desigualdades nas condições de acesso, permanência e aprendizagem na educação escolar, refletindo a complexidade de um processo em que se entrelaçam diversos fatores relativos tanto à estruturação social, política e econômica da sociedade brasileira, quanto ao trabalho pedagógico realizado no cotidiano por professores e demais profissionais nas escolas públicas.

Assim, podemos dizer que essa realidade faz parte contexto contemporâneo da Educação brasileira. Diante disso, o programa Mais Educação foi criado por meio da Portaria Interministerial no 17/2007 art. 6o inciso l, a qual implanta a educação integral por meio de atividades socioeducativas com a "ampliação do tempo e do espaço educativo de suas redes e escolas, pautada pela noção de formação integral e emancipadora", partindo do pressuposto de garantir o acesso e a permanência com aprendizagem no espaço formal de ensino (MEC/Secad, 2009).

Nesse contexto, considerando a realidade de cada um e com o intuito de propiciar o desenvolvimento dos estudantes em todas as suas dimensões cognitiva, moral, afetiva, emocional entre outras, institui-se o Decreto no 7.083/2010 com a finalidade de:

[...] contribuir para a melhoria da aprendizagem por meio da ampliação do tempo de permanência de crianças, adolescentes e jovens matriculados em escola pública, mediante oferta de educação básica em tempo integral. (BRASIL, Decreto 7083, art. 1ㅇ, 2010).

Em seu art. 3ำ são descritos os seguintes objetivos do programa:

I - formular política nacional de educação básica em tempo integral;

II - promover diálogo entre os conteúdos escolares e os saberes locais; 
III - favorecer a convivência entre professores, alunos e suas comunidades; IV - disseminar as experiências das escolas que desenvolvem atividades de educação integral; e

V - convergir políticas e programas de saúde, cultura, esporte, direitos humanos, educação ambiental, divulgação científica, enfrentamento da violência contra crianças e adolescentes, integração entre escola e comunidade, para o desenvolvimento do projeto político-pedagógico de educação integral. (BRASIL, Decreto 7083, 2010).

Segundo o documento orientador do $\operatorname{MEC}(2016$, p. 3), com a justificativa de que o Brasil não alcançou a meta estabelecida pelo Índice de Desenvolvimento da Educação Básica (IDEB) e, ainda, tem como desafio as metas 6 e 7 do Plano Nacional de Educação (PNE) que tratam da "[...] ampliação da oferta de educação em tempo integral e a melhoria da qualidade do fluxo escolar e da aprendizagem das escolas públicas", o Programa Novo Mais Educação é instituído pela Portaria no 1144 em caráter substitutivo ao Programa Mais Educação em outubro do ano de 2016.

A partir dessa perspectiva, institui-se a Portaria no1144/2016 que pontua em seu Cap. I, art. 1ㅇ o objetivo de "[...] melhorar a aprendizagem em Língua Portuguesa e Matemática no ensino fundamental [...] mediante a complementação da carga horária de cinco ou quinze horas semanais [...]" (MEC, portaria 1144, 2016).

Em continuidade, seu art. 2 o trata de sua finalidade determinando que tem o intuito de contribuir para a:

I - alfabetização, ampliação do letramento e melhoria do desempenho em língua portuguesa e matemática das crianças e dos adolescentes, por meio de acompanhamento pedagógico específico;

II - redução do abandono, da reprovação, da distorção idade/ano, mediante a implementação de ações pedagógicas para melhoria do rendimento e desempenho escolar;

III - melhoria dos resultados de aprendizagem do ensino fundamental, nos anos iniciais e finais; e

IV - ampliação do período de permanência dos alunos na escola. (MEC, portaria 1144, 2016).

\section{DISCUSSÃO}

Com base nas leituras a respeito da temática em questão, verificamos a necessidade de primeiramente compreender os princípios da Educação Integral para que, de fato, possamos acompanhar a formulação das políticas, bem como sua implementação e reformulação.

Tal ênfase a respeito do entendimento do assunto justifica-se por acreditar que somente assim, podemos pensar que o espaço escolar pode ser reconstruído e, também, reinventar a prática pedagógica para a formação do ser humano (MOLL, 2008).

De acordo com Azevedo et al (2010, p. 33), as reformas econômicas e educacionais caminham dissociadas e não no mesmo sentido, devido a isso

[...] todos os nossos esforços, sem unidade de plano e sem espírito de continuidade, não lograram ainda criar um sistema de organização escolar, à altura das necessidades modernas e das necessidades do país. Tudo fragmentado e desarticulado.

Desse modo, podemos inferir que os pressupostos da educação integral propicia pensarmos em uma formação para a cidadania e emancipação por meio da integração e articulação de ações. 
Gadotti (2009, p. 29) define que "a educação integral é uma concepção da educação que não se confunde com o horário integral, o tempo integral ou a jornada integral". Para o autor, a EI contempla duas dimensões indissociáveis: a quantitativa que está relacionada ao tempo na escola e ao seu redor e a qualitativa que refere-se à formação integral do ser humano.

Para Cavalieri (2010, p. 250) em seus estudos sobre a concepção de um dos precursores da Educação Integral no Brasil menciona que Anísio Teixeira não utilizava a expressão EI

talvez por não considerá-la suficientemente precisa e, provavelmente, para evitar qualquer identificação com os Integralistas, que, como vimos, usaram abundantemente, durante os anos 1930, as expressões "homem integral", "Estado integral" e "educação integral".

Segundo a autora, a El para Anísio Teixeira significava a ampliação da educação escolar pautada no pragmatismo americano. Este defendia que a escola não podia ser de tempo parcial porque não a via somente como uma escola de letras mas, também, como um espaço de papel relevante na "formação de hábitos de pensar e de fazer, de conviver e participar em uma sociedade democrática" (CAVALIERI, 2010, p. 256).

A partir dessa premissa, acreditava que programas com atividades práticas ampliariam as oportunidades de estudo, trabalho, arte e recreação, já que entendia que a "educação é vida e não preparação para a vida" (CAVALIERI, 2010, p. 258).

Face a esse contexto, Guará (2006, p. 16) contribui com seus saberes ao definir o ser humano na perspectiva da El:

A inteligibilidade da pessoa humana abarca a intersecção dos aspectos biológico-corporais, do movimento humano, da sociabilidade, da cognição, do afeto, da moralidade, em um contexto tempo-espacial. Um processo educativo que se pretenda "integral" trabalharia com todos estes aspectos de modo integrado - ou seja - a educação visaria à formação e ao desenvolvimento humano global e não apenas ao acúmulo informacional".

Seguindo essa mesma definição, Moll (2008) defende a premência de se pensar em uma ressignificação do espaço escolar com vistas a garantir o desenvolvimento humano em sua integralidade.

Complementa, ainda, que a escola que se propõe a seguir os pressupostos da El necessita "[...] considerar os saberes, as histórias, as trajetórias, as memórias, as sensibilidades dos grupos e dos sujeitos com os quais trabalha, tecendo as universalidades expressas nos campos clássicos de conhecimento" (MOLL, 2008, p. 15).

Gadotti (2009, p. 37), com uma visão da complexidade da temática, defende a relevância da escola como um espaço que promove o aprendizado, com ou sem ampliação de tempo, pois

Todas as escolas precisam ser de educação integral, mesmo que não sejam de tempo integral. Trata-se de oferecer mais oportunidades de aprendizagem para todos os alunos. Daí o caráter inovador dos chamados projetos de escola em tempo integral. Porque a escola burocrática, aquela que só cumpre normas, não inventa, não inova, não é rebelde.

Diante disso, podemos identificar que a finalidade do Mais educação e o objetivo do Novo Mais Educação se assemelham em relação a melhoria do aprendizado por meio da ampliação do tempo de permanência na escola.

Nesse contexto de reformulação, consideramos que essa é a fase mais importante, pois tem-se a chance de ressignificar o espaço escolar entendendo a ideia que a educação do ser humano ocorre em tempos e espaços diversos e a relevância da participação dos diferentes segmentos da sociedade. É nesse processo que a escola deve contemplar em seu Projeto Político- 
Pedagógico os princípios e ações compartilhados na direção de uma Educação Integral (PACHECO, 2008).

Entretanto, ao considerar que as interpretações podem ser diversas, nos preocupa o rumo que essa nova proposta pode tomar sendo uma delas a possibilidade de haver o distanciamento das reais finalidades da concepção de El.

Gadotti $(2009$, p. 97) complementa que

não se trata apenas de estar na escola em período integral, mas de ter a possibilidade de desenvolver todas as potencialidades humanas que envolvem o corpo, a mente, a sociabilidade, a arte, a cultura, a dança, a música, o esporte, o lazer etc.

De acordo com Azevedo et al (2010), é importante ter uma visão global do problema caso contrário, as ações ficam isoladas, fragmentadas e podemos inferir que o resultado de um aprendizado com qualidade não é alcançado.

Desse modo, Moll (2008, p. 12) afirma que a El pressupõe a construção de uma escola pública para todos e de qualidade a partir da "[...] articulação com espaços/políticas/atores que possibilitem a construção de novos territórios físicos e simbólicos de educação pública".

Segundo a autora, ao desconsiderar essa perspectiva

corre-se o risco de pensar na escola como instituição total, na política de Educação Integral como a nova panacéia para resolução dos clássicos problemas da educação pública e nas práticas de "hiper-escolarização" como resposta ao não aprender. (MOLL, 2008, p. 12).

\section{CONCLUSÃO}

A maneira que os critérios e orientações estabelecidos pelo programa Novo Mais Educação serão interpretados, implementados e reformulados por cada estado e município, é um fator preocupante ao considera-los gerais, pouco especificados e propensos a diferentes ações e impactos.

Em todo esse cenário, evidencia-se a emergência em compreender o princípio de El para posteriormente planejar e elaborar ações que de fato contemplem o ser humano em todas as suas dimensões.

Face a esse contexto, a escola tem um papel relevante mas, necessita reconstruir e reorganizar seu espaço e currículo, de maneira menos fragmentada e mais articulada com outros atores, desenvolvendo um trabalho coletivo e colaborativo.

\section{REFERÊNCIAS}

AZEVEDO, F. de (et al).Manifesto dos pioneiros da educação nova 1932 e dos educadores 1959.

Coleção Educadores MEC. Recife: Fundação Joaquim Nabuco e Editora Massangana,2010.

BRASIL. Constituição (1988). Constituição da República Federativa do Brasil: promulgada em 5 de outubro de 1988. Brasília: Senado Federal, 1988.

BRASIL. Portaria Normativa Interministerial $\mathbf{n}^{\circ} \mathbf{1 7}$, de 24 de abril de 2007. Institui o Programa Mais Educação que visa fomentar a educação integral de crianças, adolescentes e jovens, por meio do apoio a atividades sócio-educativas no contraturno escolar. Diário Oficial da União, Brasília, 2007.

BRASIL. Decreto no 7083, de 27 de janeiro de 2010. Dispõe sobre o Programa Mais Educação Diário Oficial da União, Brasília, 2007. 
BRASIL. Ministério da Educação. Secretaria de Educação Continuada, Alfabetização e Diversidade. Educação integral: texto referência para o debate nacional. Série Mais Educação. Brasília: MEC, Secad, 2009.

BRASIL. Ministério da Educação. Educação integral/educação integrada e(m) tempo integral: concepções e práticas na educação brasileira. Brasília, 2009.

BRASIL. Ministério da Educação. Secretaria de Educação Básica. Manual operacional de educação integral. Brasília, 2014.

CAVAlIERI, A. M.. Anísio Teixeira e a educação integral. Paideia, vol. 20, n. 46, mai/ago, 2010, p. 249-259. Disponível em: <http://www.scielo.br/pdf/paideia/v20n46/11.pdf>. Acesso em: 05 mai. 2016.

GADOTTI, M.. Educação integral no Brasil: inovações em processo. São Paulo: Editora e Livraria Paulo Freire, 2009.

GIL, A. C. Métodos e Técnicas de Pesquisa Social. 6ạ. Edição. São Paulo. Editora Atlas, 2012.

GUARÁ, I. M. F. R.. É imprescindível educar integralmente. Caderno CENPEC, no. 2, p. 15-24, 2006.

HOWLET, M; RAMESH, M.; PERL, A. Política pública: seus ciclos e subsistemas: uma abordagem integradora. Rio de Janeiro: Elsevier, 2013. p. 123-178.

MOLL, J.. Conceitos e pressupostos: o que queremos dizer quando falamos de educação integral? Salto para o futuro, Educação Integral, ano XVIII, boletim 13, ago., 2008.

PACHECO, S. M.. Proposta pedagógica. Salto para o futuro, Educação Integral, ano XVIII, boletim 13, ago., 2008.

PARENTE, C. da M. D.. Monitoramento do programa mais educação em Sergipe. In: PARENTE, C. da M. D.; PARENTE, J. M. (Orgs.). Avaliação, política e gestão da educação. São Cristóvão: Editora UFS, 2011.

RINALDI, R. P.; SILVA, N. S. da.. Educação Integral: entre o passado e futuro. Educação em revista, Edição Especial, v. 18, p. 121-138, 2017. Disponível em:

<http://www2.marilia.unesp.br/revistas/index.php/educacaoemrevista/article/view/6777> Acesso em: 15 abr. 2017.

SILVEIRA, R. J. T.. O professor e a transformação da realidade. Revista Nuances, vol.I, n.1, set., 2005, p. 21-30.

SUBIRATS, J. Definición Del Problema. Relevancia Pública y Formación de la Agenda de Actuación de los Poderes Públicos. In: SARAVIA, E.; FERRAREZI, E. Políticas Públicas - Coletânea. Brasília: ENAP, 2006. p. 199-218. 